\title{
Trends in the prevalence of asthma in Scottish and English primary school children 1982-92
}

\author{
Roberto J Rona, Susan Chinn, Peter G J Burney
}

\begin{abstract}
Background - Some doubts exist as to whether the increase in the prevalence of asthma is real or an artefact. The 10 year trend of asthma up to 1993 in England and Scotland was therefore assessed.

Methods - Information on asthma and bronchitis attacks, occasional wheeze, and persistent wheeze in the last 12 months, was obtained using a self administered questionnaire completed by the parents. Exactly the same questions were asked in 14 study areas in Scotland and 22 study areas in England in 1982 or 1983 and in 1992 or 1993 in 5-11 year old children.

Results - The numbers of children with data for all respiratory illness were 5556 (85.2\%) and 5801 (87.1\%) in England and $3748(90 \cdot 4 \%)$ and $3738(90 \cdot 4 \%)$ in Scotland in 1982 and 1992, respectively. There was a significant increase in asthma attacks (approximately three times more in 1992 than in 1982) and occasional wheeze (30$60 \%$ more in 1992 than in 1982) in both sexes in England and Scotland. Persistent wheeze also increased in both countries, but the increase was significant only in England (30-40\% more in 1992 than in 1982).

Conclusions - The study coincides with others that suggest that the increased prevalence of asthma may be due, in part, to changes in diagnostic behaviour. However, the continuing increase of persistent wheeze in the total sample suggests that part of the increase is real. There was no difference in the increase of persistent wheeze between Scotland and England, but the trend was only significant in England.
\end{abstract}

(Thorax 1995;50:992-993)

Keywords: asthma, persistent wheeze, trend, prevalence.

Department of Public Health Medicine, UMDS, St Thomas' Hospital,

London SE1 7EH, UK

UK J Rona

$S$ Chinn

P G J Burney

Reprint requests to: Dr R J Rona.

Received 16 February 1995 Returned to authors 6 April 1995

Revised version received 26 April 1995 Accepted for publication 7 June 1995
Although there is a consensus that the prevalence of reported asthma has increased over time, researchers disagree about the reasons for the increase. Community studies from Australia ${ }^{1}$ and the $\mathrm{UK}^{2-4}$ in school age children have shown an increase in the prevalence of asthma. However, some researchers who have shown a small increase in reported wheeze, in contrast to considerable increases in reported asthma, in questionnaires completed by the parents have favoured changes in perception, recognition, and labelling as possible explanations for the increase in the prevalence of asthma. Some studies have been difficult to interpret because either the prevalence of asthma has been estimated using different questions in the initial and final assessments, or they have included a doctor's diagnosis of asthma, or have included the recognition of asthma by the parent in the case definition. Changes in the prevalence of induced airways hyperresponsiveness have been studied in Wales ${ }^{4}$ using an exercise stimulus which is difficult to standardise and in Australia ${ }^{1}$ using histamine diphosphate. The Welsh study ${ }^{4}$ showed a significant increase in the prevalence of history of symptoms and a statistically non-significant increase of exercise-induced bronchoreactivity over a 15 year period. Only in one study has the increase in the prevalence of asthma been consistently shown by disease label, disease symptoms, and an objective assessment of asthma. ${ }^{1}$ In the UK the studies indicate a substantial increase in the prevalence of diagnosed asthma that could be due to a rise in the recognition and labelling of the condition or changes in diagnostic fashion, and a less marked but nevertheless substantial increase in the prevalence of wheeze.

In the National Study of Health and Growth we asked the same questions on respiratory illness over a 20 year period. In 1990 we reported an increase in persistent wheeze and asthma attacks in English children over the period $1973-86 .^{3}$ We decided not to report results on Scottish children then, partly because the number of Scottish children in the study between 1973 and 1982 was comparatively small, but also because of the replacement of schools which was required for a greater proportion of the total group than in England. In this report information is provided on asthma attacks, bronchitis attacks, and occasional and persistent wheeze in the period 1982-92 in England and 1982-3 to 1992-3 in Scotland. This report helps to answer two questions: firstly, whether the increase in asthma symptoms has continued to increase in England since 1982 and, secondly, whether the pattern of increase is similar in England and Scotland. The data are important because they include a large cross section of the community in England and Scotland while most other studies have covered only a small geographical area of the UK. ${ }^{245}$

\section{Methods}

Data for children aged 5-11 in 14 Scottish areas surveyed in 1982-3 and 1992-3 and in 22 English areas surveyed in 1982 and 1992 were analysed. Three English and four Scottish areas were replaced between these dates, but 
Crude prevalences, differences in prevalences (95\% CI), and age group adjusted odds ratios (OR) of respiratory symptoms and conditions (\%) for the 10 year period for English and Scottish children

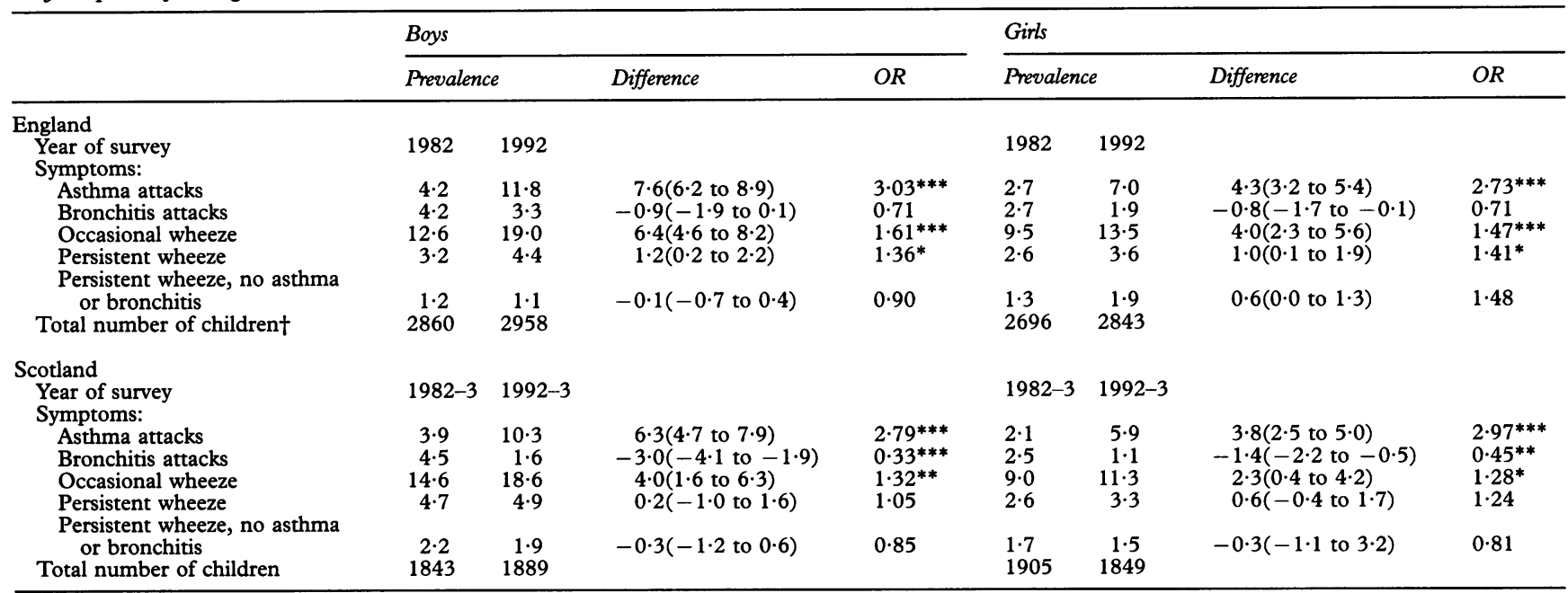

${ }^{*} \mathrm{p}<0.05,{ }^{* *} \mathrm{p}<0.01,{ }^{* * *} \mathrm{p}<0.001$ (difference from $1 \cdot 0$ ).

+ The lowest number of observations by symptom or condition given.

trends differed little when only data from nonreplaced areas were analysed. The numbers of children with all the respiratory symptoms were $5556(85 \cdot 2 \%)$ and $5801(87 \cdot 1 \%)$ in the English areas in 1982 and 1992, respectively. The corresponding numbers for Scotland were 3748 $(90 \cdot 4 \%)$ and $3738(90 \cdot 4 \%)$.

The questions assessed were: (1) Has he or she suffered from either asthma or bronchitis in the last 12 months? (2) Does his or her chest ever sound wheezy or whistling? If yes, does he or she get this on most days or nights?

Crude prevalences, differences of prevalences ( $95 \%$ confidence interval) and odds ratios for each symptom or condition adjusted for age were calculated for the 10 year period by sex and country separately.

Results

With the exception of attacks of bronchitis, there has been an increase in the prevalences of symptoms of respiratory illness in Scottish and English boys and girls (table). The increase in odds ratios adjusted for age was highly significant in both countries for asthma attacks and significant for occasional wheeze. The increase in persistent wheeze was significant in England in both sexes, but not in the Scottish children. However, the Scottish results were not significantly different from the English results. Scottish boys had a higher prevalence of persistent wheeze in the first survey in this analysis than the English boys. Bronchitis attacks have continued to decrease in England and Scotland, but to a significantly greater extent in Scottish than in English boys. The overall results show a considerable increase in asthma attacks, a moderate increase in occasional wheeze, and a mild increase in persistent wheeze. Persistent wheeze, without a reported attack of asthma or bronchitis, did not change significantly during the last 10 years. The percentage increase per year calculated from the unadjusted prevalences showed an increase of about $10 \%$ in asthma attacks per year in both countries and a decrease in bronchitis attacks per year of about 3\% in England and of $9.8 \%$ and $7.9 \%$ in Scottish boys and girls, respectively. Occasional wheeze increased by about $4 \%$ per year in England and $2 \%$ per year in Scotland. Persistent wheeze increased by about 3\% per year in England and $0.4 \%$ and $2.4 \%$ in Scottish boys and girls, respectively.

\section{Discussion}

Although the steep increase in asthma attacks in our results coincides with the findings of other British studies which indicate that the increased prevalence may be due, in part, to changes in diagnostic behaviour over time, the continuing increase in persistent wheeze in the total sample suggests that a component of the increase in asthma in the $\mathrm{UK}$ is real. Compared with our previous report in English children, ${ }^{3}$ the only meaningful difference is that of a significant increase in the prevalence of occasional wheeze. The Scottish results were not significantly different from the English results. The fact that the increase in persistent wheeze was not significant in Scotland may be due to the smaller sample size and the unusually high prevalence of persistent wheeze in the 1982-3 surveys compared with the 1984-5 surveys in Scotland (not shown). Our study supports the view that there is a moderate real increase in asthma as assessed by persistent wheeze. However, caution must be exercised in the interpretation of trend studies based on only two prevalence points.

The study was supported by the Department of Health and the Scottish Home and Health Department.

1 Peat JK, van den Berg RH, Green WF, Mellis CM, Leeder SR, Woolcock AJ. Changing prevalence of asthma in Australian children. $B M \mathcal{F}$ 1994;308:1591-6.

2 Anderson HR, Butland BK, Strachan DP. Trends in prevalence and severity of childhood asthma. BMF 1994;308: $1600-4$.

3 Burney PGJ, Chinn S, Rona RJ. Has the prevalence of asthma increased in children? Evidence from the national study of health and growth 1973-86. BMF 1990;300:1306-10.

4 Burr ML, Butland BK, King S, Vaughan-Williams E. Change in asthma prevalence: two surveys 15 years apart. Arch Dis Child 1989;64:1452-6.

5 Ninan TK, Russell G. Respiratory symptoms and atopy in Aberdeen schoolchildren: evidence from two surveys 25 years apart. $B M \mathcal{F} 1992 ; 304: 873-5$. 